\title{
The role of family and personality traits in Internet gaming disorder: A mediation model combining cognitive and attachment perspectives
}

\author{
MELINA A. THROUVALA ${ }^{1 *}$, MARI JANIKIAN ${ }^{2}$, MARK D. GRIFFITHS $^{1}$, MIKE RENNOLDSON $^{3}$ and DARIA J. KUSS ${ }^{1}$ \\ ${ }^{1}$ International Gaming Research Unit, Psychology Department, Nottingham Trent University, Nottingham, UK \\ ${ }^{2}$ School of Graduate and Professional Education, Deree - The American College of Greece, Athens, Greece \\ ${ }^{3}$ Psychology Department, Nottingham Trent University, Nottingham, UK
}

(Received: September 21, 2018; revised manuscript received: December 11, 2018; accepted: January 9, 2019)

\begin{abstract}
Background and aims: Gaming disorder was recently recognized as a mental health disorder by the World Health Organization and included in the International Classification of Diseases. Extensive research has been conducted with regard to psychosocial correlates and comorbidity, less so for the developmental mechanisms and the processes leading to the disorder. The association between family factors, personality traits, and gaming has been studied independently but not in combination. To fill this gap in knowledge, this study examined (a) the association between parental acceptance-rejection theory and Internet gaming disorder (IGD) and (b) the mediating and moderating effect of core self-evaluations (CSE), a personality construct, on the aforementioned variables. Methods: The study was quantitative and involved young adults members of online gaming communities $(N=225)$. Results: The results showed that parental rejection is associated with the occurrence of IGD, only through the mediating effect of CSE. The moderation model was not confirmed. Discussion: Findings bridge early emotional deficits with CSE personality traits and IGD, based on two widely acknowledged theoretical frameworks. In addition, they highlight the importance of the father's role in upbringing. Conclusions: These frameworks combine cognitive and attachment perspectives and a process-oriented approach to the development and maintenance of IGD. The implications of these findings are discussed in relation to (a) the mechanisms leading to the disorder and (b) providing an evidence base for therapeutic interventions for IGD to go beyond abstinence and include self-esteem enhancement and efficacy contingencies. Directions for future research are also provided in this study.
\end{abstract}

Keywords: gaming addiction, parental acceptance-rejection, PARTheory, core self-evaluations, Internet gaming disorder, attachment

\section{INTRODUCTION}

Playing video games has become one of the most valued entertainment options for approximately 2.34 billion individuals (Statista, 2018). Research has confirmed that gaming can have many positive educational, social, and therapeutic effects in a healthy context (Colder Carras et al., 2018; Granic, Lobel, \& Engels, 2014; Griffiths, Kuss, \& Ortiz de Gortari, 2017; Nuyens, Kuss, Lopez-Fernandez, \& Griffiths, 2018). However, for a minority of individuals, gaming is used in a dysfunctional way, becoming disruptive and potentially meeting criteria for addiction (Griffiths, 2005; Pontes \& Griffiths, 2015b) with impacts experienced on a cognitive, psychological, and emotional level.

Following the inclusion of Internet gaming disorder (IGD) as a condition for further study in the latest (fifth) edition of the Diagnostic and Statistical Manual of Mental Disorders (DSM-5; American Psychiatric Association, 2013), gaming disorder (GD) was recently included as a formal diagnostic entity in the 11th edition of the International Classification of Diseases (World Health Organization, 2018), referring to both offline and online games and drawing a distinction between GD and hazardous gaming. Prevalence rates for online GD differ mainly due to variability in assessment criteria and sociocultural variables (Pontes \& Griffiths, 2015b). Still, the average prevalence of disordered gaming between 1998 and 2016 did not increase in relation to Internet use increase (Feng, Ramo, Chan, \& Bourgeois, 2017). Risk factors potentially contributing to problem gaming may be conceptualized on three main pillars (Figure 1) based on the biopsychosocial model originally formulated by Engel (1977). However, the relative contribution of interpersonal relationships to the disorder has been far less explored (Bonnaire \& Phan, 2017), and there is a relative scarcity of empirical studies examining the contribution of family relationships to personality development and its relation to problem gaming. This study will examine the association between recollections of paternal and maternal-child experiences and personality traits in relation to GD.

\footnotetext{
* Corresponding author: Melina A. Throuvala; International Gaming Research Unit, Psychology Department, Nottingham Trent University, Burton Street, Nottingham, NG1 4FQ, Nottingham, UK; Phone: +44 115941 8418; E-mail: melina.throuvala@ntu.ac.uk
}

This is an open-access article distributed under the terms of the Creative Commons Attribution-NonCommercial 4.0 International License, which permits unrestricted use, distribution, and reproduction in any medium for non-commercial purposes, provided the original author and source are credited, a link to the CC License is provided, and changes - if any - are indicated. 


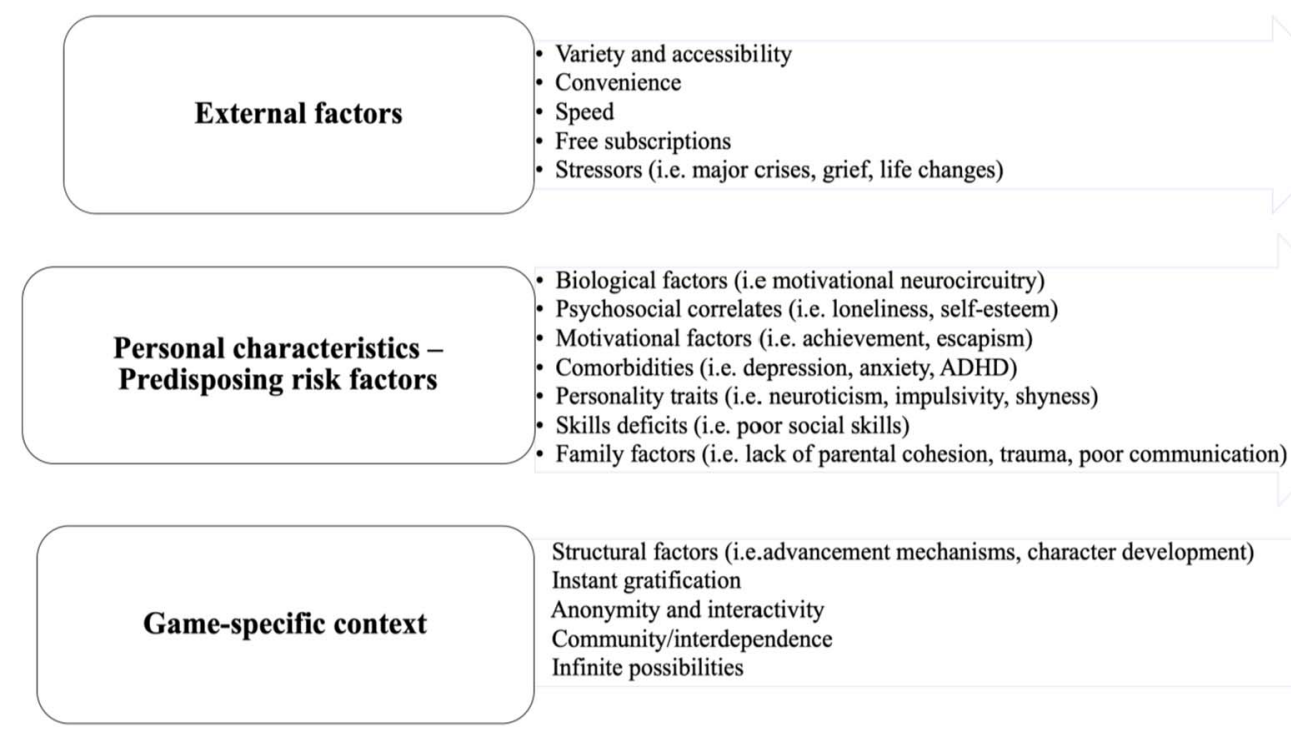

Figure 1. Risk factors associated with IGD

Emerging evidence suggests that family relationships play a critical role and may be one of the risk/protective factors associated with IGD that have been explored as perceived family disharmony (Wang et al., 2014), parental inconsistency (Kveton \& Jelinek, 2016), family dysfunction (Li, Garland, \& Howard, 2014), and poorer and conflicting family relationship (Bonnaire \& Phan, 2017; Su et al., 2018). Higher levels of family cohesion reduced IGD risk of more anxious individuals (Adams et al., 2018). A positive paternal relationship may serve as a protective factor (Schneider, King, \& Delfabbro, 2017) and parental warmth has been identified as an important contributor to child development (Zhou et al., 2002), while its lack has a unique impact on psychiatric disorders (Santesteban-Echarri et al., 2017). IGD is also associated with a host of personality traits (i.e., high neuroticism, impulsivity, and aggression) that may interact and contribute to the acquisition, development, and maintenance of IGD (Braun, Stopfer, Müller, Beutel, \& Egloff, 2016; Cole \& Hooley, 2013; Gervasi et al., 2017; Hussain \& Pontes, 2018; Kim, Namkoong, Ku, \& Kim, 2008; Laier, Wegmann, \& Brand, 2018; Mallorquí-Bagué et al., 2017).

This study aims to provide empirical evidence for the theory underlying this research, namely parental acceptancerejection theory (PARTheory; Rohner, Khaleque, \& Cournoyer, 2012) and core-self evaluations (CSE; Judge, Erez, Bono, \& Thoresen, 2002). PARTheory (Rohner, 1986; Rohner \& Khaleque, 2010; Rohner et al., 2012; Rohner \& Rohner, 1980) claims that parental acceptance and rejection (PAR) during childhood affects mental representations of self, significant others, and the world. These mental representations impact individuals' lives and guide their thoughts, affects, and behavior throughout their lives and the ways they construe and react to new experiences (Giaouzi \& Giovazolias, 2015; Rohner et al., 2012). According to PARTheory, a significant other can be any attachment figure with whom the child has established a unique, irreplaceable long-lasting emotional bond. Recollection of these positive or negative experiences comprises the warmth dimension of parenting with parental acceptance signifying the warmth, affection, care, nurturance, and support that children can experience from their parents and other caregivers, and parental rejection, the absence or emotional availability, by any combination of four principal expressions (Figure 2) that may not concern the parents' actions, but rather the child's beliefs (Rohner et al., 2012).

CSE is a specific form of self-concept, a personality constellation that represents fundamental appraisals that individuals develop regarding themselves, other people, and the world (Judge, Locke, \& Durnham, 1997), consisting of four individual personality-related traits: (a) self-esteem, an individual's sense of self-worth or value; (b) generalized self-efficacy, the assessment of one's ability to achieve a goal or an outcome in various daily situations; (c) neuroticism, a tendency to express emotional instability, rumination, and negativity; and (d) locus of control, the internal or external attribution of events affecting an individual (Judge et al., 1997). Judge et al. (2002) propose that these personality constructs have a relatively permanent quality and influence evaluations about self and others. CSE was conceptualized as a latent psychological construct (Erez \& Judge, 2001; Judge et al., 2002; Judge, Locke, Durham, \& Kluger, 1998) as the four traits share many conceptual similarities, indicating a common factor forming a higher order construct (Erez \& Judge, 2001; Judge, Bono, \& Locke, 2000; Judge et al., 1998). CSE has been associated with work and life variables (Grant \& Sonnentag, 2010; Judge, Hurst, \& Simon, 2009; Kammeyer-Mueller, Judge, \& Scott, 2009; Koumoundourou, Tsaousis, \& Kounenou, 2011; Nikolaou \& Tsaousis, 2002; Rosopa \& Schroeder, 2009) and with Internet addiction (Geng, Han, Gao, Jou, \& Huang, 2018).

A major construct underlying CSE is self-esteem. The sense of personal worth is recognized as a primary psychological mechanism for human functioning and is defined as an evaluation of one's self-concept mirrored on appraisals, social comparisons, and self-attributions (Rosenberg, Schooler, \& Schoenbach, 1989). A large number of studies have associated problematic gaming behavior or IGD with low selfesteem (Beard, Haas, Wickham, \& Stavropoulos, 2017; 


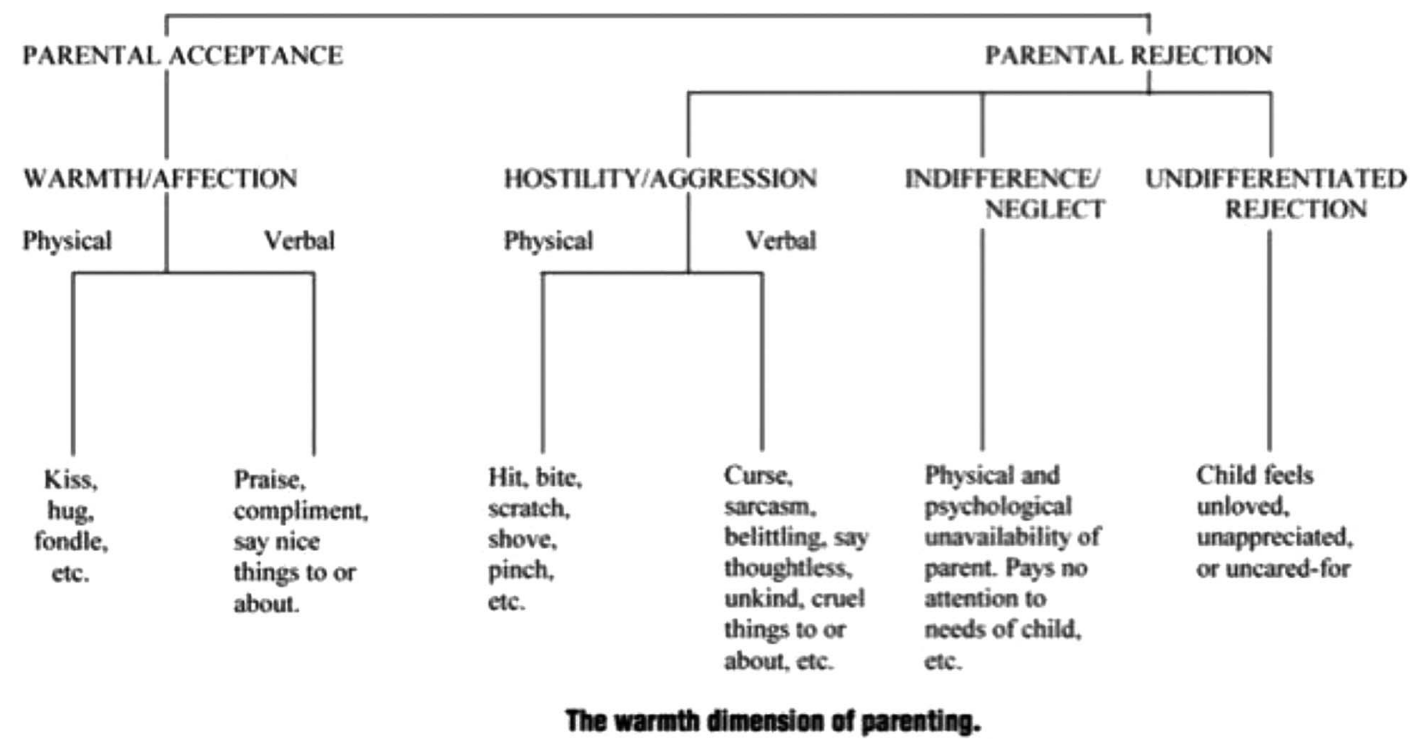

Figure 2. Theoretical model of the warmth dimension of parenting according to PARTheory and its behavioral manifestation to children (Rohner et al., 2012)

Ko, Yen, Chen, Chen, \& Yen, 2005; Lemmens, Valkenburg, \& Peter, 2011; Sincek, Humer-Tomasic, \& Duvnjak, 2017; Wartberg et al., 2017). Players have been found to depend on gaming to gain self-esteem, to compensate for weak self-image by exhibiting mastery, escaping reality or overcoming difficulties in social interaction (Douglas et al., 2008; King \& Delfabbro, 2014; Lemmens et al., 2011; Williams, Yee, \& Caplan, 2008).

Self-efficacy, an individual's appraisal of what one is capable of accomplishing in a given setting, is defined as the absolute trust in one's abilities to produce outcomes (Bandura, 1977). Evidence suggests that there is a negative association between general self-efficacy, competence, gaming-contingent self-worth and IGD with maladaptive cognitions, and negative thoughts about the world (Allison, von Wahlde, Shockley, \& Gabbard, 2006; Beard \& Wickham, 2016; Davis, 2001; Lo, Wang, \& Fang, 2005), suggesting an impaired self-concept among addicted gamers, whereas game self-efficacy has a positive impact on IGD (Jeong \& Lee, 2015), and warm parenting style on self-efficacy of adolescents (Kausar \& Kazmi, 2011).

One of the personality traits that has been most associated with gaming addiction is neuroticism (e.g., Braun et al., 2016; Gervasi et al., 2017; Jeong \& Lee, 2015; Kuss, Griffiths, \& Binder, 2013; Kuss, Shorter, van Rooij, van de Mheen, \& Griffiths, 2014; Mehroof \& Griffiths, 2010; Müller, Beutel, Egloff, \& Wölfling, 2014). However, there have been contradictory findings based on game genre (Braun et al., 2016; Graham \& Gosling, 2013).

There is evidence suggesting that locus of control, a belief system reflecting the extent to which people perceive personal or external control over their life (Chak \& Leung, 2004), is directly related to IGD. Individuals with external locus of control exhibit a higher association between experiential motives (concentration, enjoyment, and escape) and intention to play online games (Koo, 2009), suggesting lesser faith in one's own ability and more external attribution to chance or other external factors in determining the course of an event.
The findings of the previous study, as outlined above, contribute to the hypothesis that individual CSE traits may mediate excessive gaming behavior (Beard \& Wickham, 2016; Gervasi et al., 2017; Scerri, Anderson, Stavropoulos, $\& \mathrm{Hu}, 2018)$. In addition, there is evidence of the role of maternal and paternal rejection (PARTheory) in predicting impaired self-esteem and/or self-efficacy (Chong, Yeo, \& Mislan, 2014; Dural \& Yalcin, 2014). However, to the authors' knowledge, these three constructs have never been examined in relation to each other and this study attempts to fill this gap in knowledge. Under this perspective, CSE will be tested as a potential psychosocial factor and it will be determined whether the fundamental appraisal mechanism regarding the worthiness, effectiveness, and capability of a gamer can mediate and/or moderate the relationship between parental rejection and their addictive gaming activity. The hypotheses comprised the following:

Hypothesis 1: Perceived parental rejection will be positively related to IGD.

Hypothesis 2: Perceived parental rejection will be negatively related to CSE.

Hypothesis 3: CSE will be negatively correlated with IGD. Hypothesis 4: CSE will mediate the relationship between perceived PAR and IGD.

Hypothesis 5: CSE will have a moderating effect on the relationship between perceived PAR and IGD. More specifically, CSE will moderate the relationship between PAR and IGD, such that the relationship between PAR and IGD exists only for people with low CSE and not for individuals with high CSE.

\section{METHODS}

\section{Participants}

The sample comprised gamers belonging to various Greek gaming communities on Facebook. Participants were recruited through a post on various mainly online and few 
offline Greek gaming community pages asking for volunteer adult gamers. Inclusion criteria were being an online gamer and at least 18 years old. Originally, a total of 225 young adults (29 females and 196 males) voluntarily participated in the study after viewing the posted message, and 172 were assessed to meet abuse and addiction levels according to the instrument's cut-off scores. The sample was homogeneous in terms of Greek ethnicity.

\section{Measures}

Participants completed a battery of scales comprising sociodemographic information and three self-report scales to assess IGD, PAR, and CSE, based on existing reliability and validity data, brevity of measures, and the range of items covered across the measures.

Scale for the Assessment of Internet and Computer Game Addiction (AICA-S; Wölfling, Müller, \& Beutel, 2010). The AICA-S is a 13-question, 5-point Likert scale, self-report scale assessing IGD according to criteria adapted from gambling and substance-related disorders in DSM IV-TR. Assessment ranges from non-problematic (0-6.5 points; fewer than two criteria fulfilled; non-problematic group), at-risk (7-13 points; two to four criteria met; at-risk group) to addictive use, indicating IGD (13.5 points; five or more criteria met; IGD group) as a weighted sum score from the results of the diagnostic items. According to previous studies, AICA-S displays sound psychometric properties (Kuss, Shorter, van Rooij, Griffiths, \& Schoenmakers, 2013; Müller, Beutel, \& Wölfling, 2014; Wölfling, Müller, \& Beutel, 2011). The scale was adapted to Greek language and validated in a large cross-national study ( $N=12,938$; Müller et al., 2015). In this study, Cronbach's $\alpha$ for AICA-S was .70, with interitem reliability ranging from $\alpha=.65$ to .70 .

Adult Parental Acceptance-Rejection Questionnaire (Adult PARQ): Father and Mother - Short Form (Rohner, 2005). The Adult PARQ is a self-report scale that assesses the way adult participants perceived their parents' acceptance-rejection when they were around 6-12 years old. Therefore, it assesses participants' recollections of childhood experiences with items referring to specific parental behaviors or the recollected perceived feeling experienced by the adult when the individual was a child (i.e., "I felt loved"). The scale includes 24 items (12 for each parent), consisting of four constructs: (a) warmth, (b) aggression, (c) neglect, and (d) undifferentiated rejection. Examples of these items include "Said nice things about me" and "Made me feel wanted and needed." Higher scores designate perceived acceptance by their caregivers during childhood, and lower scores in this dimension indicate rejection. The Adult PARQ (Rohner, 2005) is an empirically validated instrument (Khaleque \& Rohner, 2002) with high internal consistency (Cronbach's $\alpha=.95$ and .94 for father and mother versions, respectively), adapted into Greek (Tsaousis, Giavazolias, \& Mascha, 2010) and validated in the Greek context (Giaouzi \& Giovazolias, 2015; Giovazolias, 2014). Evidence suggests strong convergent and divergent validity for the instrument in an international context (Rohner \& Khaleque, 2005).
Core Self-Evaluations Scale (CSES; Judge, Erez, Bono, $\&$ Thoresen, 2003). The CSES is a 12-item, 5-point Likert scale that measures the CSE construct. It is a direct assessment of the construct rather than an indirect measurement of the construct indicators (i.e., self-esteem, generalized self-efficacy, locus of control, and neuroticism). Example items include "I complete tasks successfully," "Overall, I am satisfied with myself," and "Sometimes I feel depressed." The instrument was adapted into Greek (Tsaousis, Nikolaou, Serdaris, \& Judge, 2007) and used in a variety of studies (Koumoundourou et al., 2011; Tsaousis et al., 2007; Tsaousis, Karademas, \& Kalatzi, 2012). Psychometric properties for the CSES have been strong and the instrument loaded on a single dimensional construct (Judge et al., 2003). All scores were summed to produce a single unified score. Cronbach's $\alpha$ for CSE in this study was .80 .

\section{Statistical analyses}

To test the hypothesis of mediation, the data were analyzed using SPSS 22.0 (Armonk, NY, USA) and PROCESS Model 4 (Hayes, 2012, 2013; Hayes \& Matthes, 2009; Preacher \& Hayes, 2004, 2008; Preacher, Rucker, \& Hayes, 2007) using a non-parametric resampling method bootstrap with 5,000 bootstrapped samples, bias-corrected $95 \%$ confidence intervals, to probe conditional indirect effects for the different PAR dimensions via the hypothesized mediator (CSE) on IGD. The sample size of 172 individuals was considered adequate for six of the most common and most recommended tests for mediation, when examining various parameters (Fritz \& Mackinnon, 2007). Eight different mediation and moderation analyses were performed for each one dimension of PAR. Moderation analysis was performed corresponding to Model 1 of the PROCESS tool. According to this model and to the predicted hypothesis, the moderator (CSE) was assumed to affect the path from PAR to IGD only for individuals who exhibited low levels of CSE.

\section{Ethics}

Before completing the survey, all participants were presented with a brief written explanation of the study and were informed of their rights as participants (American Psychological Association, 2010). This research study was reviewed and approved by the Institutional Review Board on Research with Human Participants at Deree - The American College of Greece.

\section{RESULTS}

The participants were all gamers, which was an inclusion criterion for the study. As already stated, 172 of 225 participants met IGD criteria (scored within the AICA-S cut-off points for abuse and addiction) and were included in the analyses. Participants were primarily male $(87 \%)$ and University students $(69 \%)$, between $18-24$ years $(66 \%)$ and single $(59 \%)$, while $36 \%$ reported being in a relationship. A total of $13 \%$ reported a past psychiatric illness, with 
depression being the most prevalent. The mean score on the AICA-S was $11.56(S D=3.06)$ and maximum gaming hours reported per day were $20 \mathrm{hr}$, and for weekend use were $24 \mathrm{hr}$. Three quarter and below (73\%) scored between 7 and 13, signifying abuse (2-4 criteria met; at-risk group), and 25\% and above scored for addiction (5 or more criteria met; IGD group). More specifically, mean hours spent per weekday gaming were $5.76 \mathrm{hr}(S D=4.15)$ and during weekend days or holidays were $4.54 \mathrm{hr}(S D=5.14)$. The final sample comprised 172 gamers (150 men and 22 women) with a mean age of 23.3 years $(S D=1.83)$. The majority $(80 \%)$ played more than one game: multiplayer online battle arena (i.e., Lol, Dota $2 ; 82 \%$ ), massively multiplayer online roleplaying games (i.e., WoW; 60\%), shooter games (first-person shooter/third-person shooter games; $30 \%$ ), followed by roleplaying games (i.e., Diablo; 14\%), and simulation games (i.e., War Thunder; 10\%). Bivariate correlations and Cronbach's $\alpha$ for all the variables are presented in Tables 1 and 2. All statistics were two-tailed with a .05 level of significance.

Hypothesis 1: Perceived parental rejection was positively correlated with IGD. Contrary to expectations, there was a positive but non-statistically significant correlation between PAR and IGD with all PAR subscales (father and mother), ranging from $r=.04$ ( $p=.60$; indifference father) to $r=.12 \quad(p=.10$; undifferentiated mother), suggesting there is no evidence of a direct relationship.

Hypothesis 2: The results indicated that perceived parental rejection was negatively correlated with CSE, confirming the second hypothesis. Both maternal and paternal PAR were negatively correlated with CSE on all measures (Table 1).

Hypothesis 3: The third hypothesis was also confirmed. CSE was negatively correlated with IGD and it was a statistically significant correlation $(r=-.31, p<.001)$, suggesting that the lower the CSE, the higher the gaming activity and vice versa.
Table 2. Means, standard deviation (SD), and Cronbach's $\alpha$ for all measures

\begin{tabular}{lrcc}
\hline Subscales & Mean & $S D$ & Cronbach's $\alpha$ \\
\hline Warmth/affection - Father & 18.18 & 4.55 & .72 \\
Hostility/aggression - Father & 9.31 & 3.72 & .82 \\
Indifference/neglect - Father & 10.36 & 3.81 & .80 \\
Undifferentiated rejection - & 5.41 & 2.36 & .84 \\
$\quad$ Father & & & \\
Warmth/affection - Mother & 16.06 & 4.33 & .76 \\
Hostility/aggression - Mother & 9.80 & 3.93 & .84 \\
Indifference/neglect - Mother & 8.47 & 3.16 & .84 \\
Undifferentiated rejection - & 5.27 & 2.26 & .84 \\
$\quad$ Mother & & & \\
Core self-evaluation (CSE) & 40.84 & 7.60 & .80 \\
Internet gaming disorder & 11.55 & 3.06 & .67 \\
$\quad$ IGD) & & & \\
Hours per day & 5.76 & 4.15 & - \\
Weekend/holiday use (hr) & 4.54 & 5.14 & - \\
\hline
\end{tabular}

Hypothesis 4 (mediation by CSE): It was hypothesized that CSE would mediate the relationship between perceived PAR and IGD (Figure 3 and Table 3 for each variable). However, in this study, PAR was found to influence IGD only via the mediating factor of CSE.

All mediation analyses performed for this study confirmed the mediating effects of CSE on the relationship between PARQ dimensions on IGD (Table 3) and all the correlation coefficients were in the moderate levels. For example, paternal indifference significantly predicted CSE (path a; $b=-0.47, t=-3.32, p=.01$ ) and this in turn significantly predicted IGD (path $\mathrm{b} ; b=-0.12$, $t=-4.02, p=.01 ;$ path $\mathrm{c} ; b=-0.02, t=-4.17, p=.63)$. When CSE was entered in the model, the analysis showed that there was a mediation effect on the relationship between PAR and IGD. A significant indirect effect was observed of indifference father on IGD via CSE

Table 1. Correlation coefficients for PAR, CSE, and IGD variables $(N=172)$

\begin{tabular}{|c|c|c|c|c|c|c|c|c|c|c|c|}
\hline & Subscales & 1 & 2 & 3 & 4 & 5 & 6 & 7 & 8 & 9 & 10 \\
\hline 1. & Warmth/affection - Father & & & & & & & & & & \\
\hline 2. & $\begin{array}{l}\text { Hostility/aggression - } \\
\text { Father }\end{array}$ & $.51 * *$ & & & & & & & & & \\
\hline 3. & $\begin{array}{l}\text { Indifference/neglect - } \\
\text { Father }\end{array}$ & $.76^{* *}$ & $.48^{* *}$ & & & & & & & & \\
\hline 4. & $\begin{array}{l}\text { Undifferentiated rejection - } \\
\text { Father }\end{array}$ & $.65^{* *}$ & $.78 * *$ & $.67 * *$ & & & & & & & \\
\hline 5. & Warmth/affection - Mother & $.31 * *$ & $.23 * *$ & $.32 * *$ & $.29 * *$ & & & & & & \\
\hline 6. & $\begin{array}{l}\text { Hostility/aggression - } \\
\text { Mother }\end{array}$ & $.17^{*}$ & $.39 * *$ & $.32 * *$ & $.33 * *$ & $.62 * *$ & & & & & \\
\hline 7. & $\begin{array}{l}\text { Indifference/neglect - } \\
\text { Mother }\end{array}$ & $.31 * *$ & $.43^{* *}$ & $.44 * *$ & $.43^{* *}$ & $.69 * *$ & $.63^{* *}$ & & & & \\
\hline 8. & $\begin{array}{l}\text { Undifferentiated rejection - } \\
\text { Mother }\end{array}$ & $.18^{*}$ & $.41^{* *}$ & $.35^{* *}$ & $.47 * *$ & $.56^{* *}$ & $.76^{* *}$ & $.71 * *$ & & & \\
\hline 9. & $\begin{array}{l}\text { Internet gaming disorder } \\
\text { (IGD) }\end{array}$ & .08 & .08 & .04 & .10 & .08 & .09 & .06 & .12 & & \\
\hline 10. & Core self-evaluation (CSE) & $-.19 *$ & $-.25 * *$ & $-.24 * *$ & $-.34 * *$ & $-.29 * *$ & $-.32 * *$ & $-.27 * *$ & $-.31 * *$ & $-.31 * *$ & \\
\hline
\end{tabular}

Note. PAR: parental acceptance and rejection.

${ }^{*} p<.05 . * * p<.001$. 


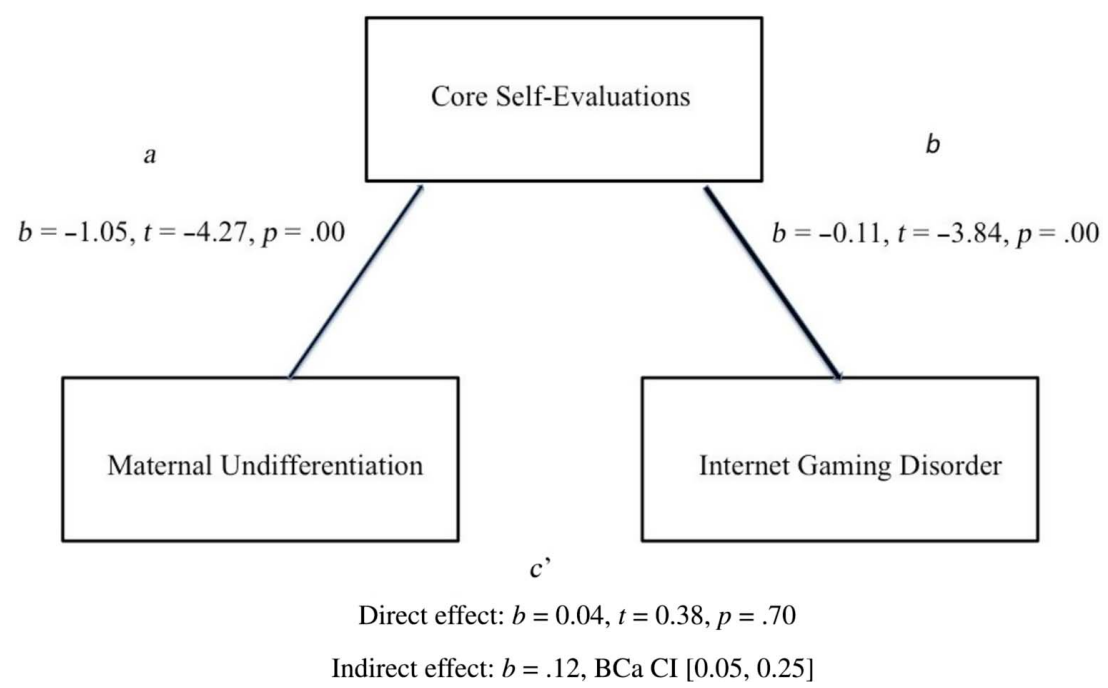

Figure 3. The indirect effect of maternal undifferentiation on Internet gaming disorder through core self-evaluations

Table 3. Mediation results for PAR, CSE, and IGD variables $(N=172)$

\begin{tabular}{lcccccrrr}
\hline Variables & $a b(B)$ & $\mathrm{LL}$ & $\mathrm{UL}$ & $a$ & $b$ & $c$ & $c^{\prime}$ & $\kappa^{2}$ \\
\hline 1. Warmth/affection - Fa & 0.04 & 0.01 & 0.08 & -0.32 & -0.12 & 0.06 & 0.02 & 0.06 \\
2. Hostility/aggression - Fa & 0.05 & 0.02 & 0.12 & -0.50 & -0.12 & 0.06 & 0.00 & 0.08 \\
3. Indifference/neglect - Fa & 0.06 & 0.02 & 0.11 & -0.47 & -0.12 & 0.03 & -0.02 & 0.08 \\
4. Undifferentiated rejection - Fa & 0.10 & 0.05 & 0.20 & -0.86 & -0.12 & 0.11 & 0.01 & 0.08 \\
5. Warmth/affection - Mo & 0.06 & 0.03 & 0.12 & -0.50 & -0.12 & 0.05 & -0.00 & 0.09 \\
6. Hostility/aggression - Mo & 0.07 & 0.03 & 0.14 & -0.62 & -0.12 & 0.07 & -0.00 & 0.10 \\
7. Indifference/neglect - Mo & 0.08 & 0.03 & 0.15 & -0.64 & -0.12 & 0.05 & -0.02 & 0.08 \\
8. Undifferentiated rejection - Mo & 0.12 & 0.04 & 0.25 & -1.04 & -0.11 & 0.16 & 0.04 & 0.09 \\
\hline
\end{tabular}

Note. B: unstandardized $\beta$ coefficients; Fa: father; Mo: mother; $a$ : the slope of the mediator (CSE) regressed on the independent variable (PAR); $b$ : the slope of the outcome (IGD) regressed on the mediator (CSE); $a b$ : the indirect effect; $c$ : the slope of the outcome (IGD) regressed on the independent variable (PAR); $c^{\prime}$ : the slope of the outcome (IGD) regressed on the independent variable (PAR) controlling for the mediator (CSE); LL: lower limit; UL: upper limit; $\kappa^{2}$ : an index of "the proportion of the maximum possible indirect effect" (Preacher \& Kelley, 2011, p. 43).

$(\mathrm{a} \times \mathrm{b}: \quad b=0.06, \quad \mathrm{BCa} \mathrm{CI}=[0.02,0.12])$, indicating mediation. This represented a medium effect size $\left(\kappa^{2}=0.08,95 \%\right.$ BCa CI $\left.[0.03,0.14]\right)$.

Hypothesis 5 (moderation by CSE): Eight different moderation analyses were conducted. For example, in the warmth father dimension, the moderating effect of CSE in the relationship between paternal warmth and IGD was examined. In the first step, it was found that paternal warmth did not predict IGD $(b=0.02, t=0.68, p=.69$, $\mathrm{BCa}$ CI $[-0.086,0.130])$. Second, it was found that the interaction between paternal warmth (coldness) and CSE did not have a statistically significant effect on IGD $(b=$ $0.012, t=2.08, p=.87$, BCa CI $[0.00,0.02])$. This hypothesis was not confirmed for any of the tested models.

\section{DISCUSSION AND CONCLUSIONS}

Although numerous studies on IGD have been conducted in recent years, few studies have examined the role of family and personality traits in the development of IGD. This study investigated how IGD was shaped by the indirect effect of CSE and the interaction effect between two factors external to gaming: parental rejection and CSE. The results of the study demonstrated that (a) PAR was not associated with addictive gaming (Hypothesis 1), (b) PAR was negatively correlated with CSE (Hypothesis 2), and (c) CSE was negatively correlated with IGD (Hypothesis 3). However, an interesting relationship emerged (Hypothesis 4). CSE mediated the relationship between PAR and IGD, supporting this hypothetical mechanism of mediation: the more rejection an individual has experienced during early childhood, the more likely that individual was to develop a low CSE (i.e., low self-esteem, a diminished sense of selfefficacy, an imbalanced locus of control, and heightened levels of neuroticism), potentially leading to more pathological gaming behavior as a result. The findings provide a possible etiological link between a maladaptive contingency and a deficient childhood through the development of an impaired CSE, and highlighted a process-oriented approach in the development of IGD. However, contrary to predictions, the results showed no moderation effects of CSE on 
the relationship between PAR and IGD (Hypothesis 5). This is potentially because parental rejection, as measured through PARTheory, refers to the past - recollections of parental care between 6-12 years of age - and fails to establish an association to a current dysfunctional activity, namely problematic gaming.

The first hypothesis, which also serves as a prerequisite condition for the mediation, was not confirmed. However, Shrout and Bolger (2002) suggest the possibility that the predictor might not necessarily correlate with the outcome variable - when by previous researchers this was considered a prerequisite condition (Baron \& Kenny, 1986). This holds especially for developmental research, when the variables assessed are distant chronologically (i.e., adolescent behavior problems resulting in adult psychopathology), as the effect is probably subtle and therefore may not be reflected in results. MacKinnon, Lockwood, Hoffman, West, and Sheets (2002) recommended that "studies of such distal processes proceed without the initial bivariate test of the long-term effects and that the test of the model-based association through the indirect path be approached through the bootstrap procedure or other recommended methods" (Shrout \& Bolger, 2002, p. 430). Gaming addiction should be viewed in the wider context of emerging adulthood to be more comprehensively understood. Emergent adulthood forms a critical and distinct developmental period from 18 to 29 years, signifying a transition from late adolescence into early adulthood, with critical processes taking place for identity development and consolidation characterized by: exploration, instability, self-focus, feeling in-between and optimism - with increased volition over options and considerable independence from social norms and expectations (Arnett, 2000; Arnett, Žukauskienè, \& Sugimura, 2014; Pavis, Cunningham-Burley, \& Amos, 1998). This demographically and subjectively distinct period, which became normative over the past few decades, appears to be reinforced in the digital age. Longitudinal evidence suggests a delayed developmental trajectory in adolescence, with a delayed onset of adult commitments and activities (i.e., work for pay, dating, and driving; Bleidorn \& Schwaba, 2017; Twenge \& Park, 2017; Twenge et al., 2010; Twenge, Joiner, Rogers, \& Martin, 2018). Late adolescence is prolonged both chronologically and in terms of psychosocial development with significant implications and mental health challenges.

Therefore, the developmental period of emergent adulthood presents - distinctively to adolescence - increased vulnerability for the development of gaming addiction, psychiatric disorders, and psychosocial problems (Hein \& Berman, 2016) partially due to: (a) increased autonomy and freedom to define work/study/leisure choices and a delay in commitments to adult roles and openness to experience (Bleidorn \& Schwaba, 2017; Layland, Hill, \& Nelson, 2018); (b) anxiety and ambivalence associated with abundant choice in relation to employment, education, relationship formation, and independent living (McMillin, 2017); (c) differential developmental trends in emotion regulation strategies and novelty-seeking behaviors (Hussain, Williams, \& Griffiths, 2015; Mitchell, Gao, Hallett, \& Voon, 2016; Zimmermann \& Iwanski, 2014); (d) personality development that continues past adolescence (Roberts \& Davis, 2016); (e) contextual factors such as less physical activity, or other adult activities that may create "role incompatibility" with time spent online (Corder et al., 2017; Henchoz et al., 2016; Ream, Elliott, \& Dunlap, 2013); and (f) increased time spent on media for need gratification (Coyne, Padilla-Walker, \& Howard, 2014).

The mediation findings of this study confirm the theoretical postulations of PARTheory (Rohner et al., 2012) and are in line with other theoretical frameworks and empirical findings: PARTheory reflects that parental warmth rejection plays a major role in identity and personality formation and shapes attitudes and dispositions, and that impairment in personality disposition will lead children to have low capacity to manage stress and eventually end up with a life crisis. This is also in accordance with fundamental principles underlying classic developmental psychological theories and attachment theory that link early parental experiences to subsequent emotional and personality development and the potential occurrence of psychopathological symptoms (Blom \& Bergman, 2013; Hughes, Blom, Rohner, \& Britner, 2005). However, PARTheory emphasizes behavioral manifestations as a result of deficient upbringing, providing a cognitive perspective (perceived parental rejection) in addition to the attachment perspective. This implies cognitive processing that takes place and may be implicated in the cognitive rigidity and distortions or the cognitive impairments encountered in gamers (King \& Delfabbro, 2014; Pontes \& Griffiths, 2015a; Wu, Sescousse, Yu, Clark, \& Li, 2018).

In addition, an extensive body of empirical data provides further support to the findings. It could be suggested that low CSE, shaped by poor family experiences, may lead to higher gaming involvement, potentially to enhance low self-esteem and efficacy levels. Attachment orientation and identity styles were found in recent studies to predict nonsubstance-related addictions (Estévez, Jáuregui, SánchezMarcos, López-González, \& Griffiths, 2017; Monacis, de Palo, Griffiths, \& Sinatra, 2017; Schimmenti \& Caretti, 2017), and CSE to be negatively correlated with Internet addiction (Geng et al., 2018). IGD research demonstrates an association between excessive gaming and low self-esteem (Kardefelt-Winther, 2014; Kim \& Davis, 2009; Li, Liau, \& Khoo, 2011; Van Rooij et al., 2014). Quality of attachment with parents and peers has also been found to have an impact on academic, social, and emotional functioning in emergent adulthood (Holt, Mattanah, \& Long, 2018), with avoidant and anxious attachment attitudes influencing the onset and maintenance of problematic Internet use in late adolescence, even when attachment trauma is controlled for (Schimmenti, Passanisi, Gervasi, Manzella, \& Famà, 2014). Vulnerability experienced during childhood signifies a lack of security and trust in subsequent adult relationships that may lead to poor self-perception, self-efficacy, and difficulties experienced in relationships with peers. These deficits in turn may lead to dissociation (i.e., the defense mechanism of preventing painful experiences from entering into consciousness) from real-life activities and escapism into virtual worlds to gratify those unmet needs of security, worthiness, and relatedness, which further promote a pathological 
engagement with games. Specifically, dissociation was found to mediate the relationship between attachment disorganization (an attachment style fostered by fearful experiences with parent/carer or unavailability to child's distress; Lyons-Ruth \& Spielman, 2004) and Internet addiction (Schimmenti, Guglielmucci, Barbasio, \& Granieri, 2012). These mediation processes highlight a potential developmental pathway between attachment styles and the development of gaming addiction.

Moreover, studies have demonstrated the partial appeal of video games due to the experience of an ideal virtual self that would not otherwise find expression in everyday life (Li et al., 2011; Przybylski, Weinstein, Murayama, Lynch, \& Ryan, 2012), providing character attachment - the psychological merging of the player's and the character's mind (Bessière, Seay, \& Kiesler, 2007; Bowman, Schultheiss, \& Schumann, 2012). This identification has been found to alter neural correlates of self (Choi et al., 2018). Feelings of achievement and competence enhance self-esteem via the provision of in-game challenges along with continuous performance ratings (Kazakova, Cauberghe, Pandelaere, \& De Pelsmacker, 2014). Contingent self-esteem then becomes a condition for individuals who experience their worth based on outcomes (Deci \& Ryan, 1985), prone to introjection, a purposive behavior arising from the need to obtain external approval for one's actions (Brown \& Ryan, 2003), with gaming addiction providing additional reassurance of worth (Burnay, Billieux, Blairy, \& Laroi, 2015).

An alternative explanation for those with low CSE could be that gaming helps to counteract the effects of negative feelings and stressful experiences, regulating distressing emotions (Stetina, Kothgassner, Lehenbauer-Baum, \& Kryspin-Exner, 2011), serving as a dysfunctional coping strategy (Laconi, Pirs, \& Chabrol, 2017). Gaming in this case acts as a "psychic retreat" (Steiner, 1993), a withdrawal reducing emotional distress or turmoil and acting as a buffer or an outlet and a temporary escape. High neuroticism levels (the third trait of CSE) have also been implicated with video game playing for diversion, stress reduction, or relief (Chory \& Goodboy, 2011). Research indicates that emotional stability may be associated with stress and coping style: individuals with low CSE use avoidance coping, characterized by destructive behaviors, and avoiding stressful situations (Billings \& Moos, 1981) or as a stress buffer - especially by those with emotion-focused coping style and individuals with less social support (Reinecke, 2009). However, other research findings dispel the myth of withdrawn and emotionally dissatisfied, lonely individuals and evidence psychological profiles of confident, social individuals with the core motivation being the rewarding nature of gaming, in-game achievement, and in-game social interactions (Billieux et al., 2015; Herodotou, Kambouri, \& Winters, 2014). Consequently, the current research demonstrates that addictive online gaming is a heterogeneous, complex, and contextual disorder with versatility in its manifestation (Throuvala, Griffiths, Rennoldson, \& Kuss, 2018c).

This study also demonstrated that there was an almost equally (to mother) strong negative correlation between perceived father rejection and CSE traits. This finding magnifies the role of the father in upbringing and suggests that fathers have a protective role (Schneider et al., 2017) and should engage in warmth parenting to nurture children with healthier psychological adjustment and a heightened self-esteem as young adults (Chong et al., 2014). Paternal love is associated with children's and adults' major facets of psychological, social, emotional, and cognitive development, well-being, delinquency, and behavior problems (Biller \& Borstelmann, 1967; Booth \& Amato, 1994; Rohner \& Veneziano, 2001). Males' self-esteem has been found to depend upon paternal continuous contact and maternal leisure time spent together with the child (Barber \& Thomas, 1986). Deficits in parental functions lead to maladaptive contingencies of self-worth and a fluctuating self-esteem based on performance, which may be associated with problematic conditions (Beard \& Wickham, 2016; Mageau, Carpentier, \& Vallerand, 2011).

This study has some critical theoretical and clinical implications. At a theoretical level, it extends a processoriented approach in understanding IGD in a socialecological context, as with substance use disorders (Connell, Gilreath, Aklin, \& Brex, 2010; Gruenewald, Remer, \& LaScala, 2013). Increasingly, the systemic and multimodal treatment approach appears more effective than sole focus on cognitive-behavioral aspects that partially address the dysfunction (Day, 2017; Kuss \& Lopez-Fernandez, 2016; Throuvala, Griffiths, Rennoldson, \& Kuss, 2018a, 2018b; Torres-Rodríguez, Griffiths, \& Carbonell, 2017).

In terms of practical implications, this study reinforces insights on the treatment of GD, which requires work at an intrapsychic level to identify and address those insecure or ambivalent internal working models of attachment that define subsequent emotional states, ways of relating with others, and feelings of safety in adulthood (Pietromonaco \& Barrett, 2000; Schimmenti et al., 2012, 2014). Failure to satisfy those primary attachment needs may impede subsequent treatment work that is necessary to overcome the state of regression, ritualistic self-absorption, and dependence that defines addictive video game engagement. Goals can then be set for more adaptive functioning, such as selfesteem and self-efficacy enhancement, the adoption of more functional coping strategies, and training in interpersonal skills development - as highlighted in previous studies (Kuss \& Pontes, 2019).

At a family and school level, these findings emphasize the role of the family in prevention programs and the role of schools in recognition and early detection of the disorder (Delfabbro et al., 2018; Throuvala et al., 2018b). Interventions targeting the family and schools may aim to raise awareness of the disorder and of the main drivers and issues involved in problematic gaming (i.e., structural characteristics of games, addressing gambling aspects in games, benefits vs. harms, principles of reinforcement, distinction between normative vs. pathological gaming, where to look for help and evidence) and focus on improving parent-child communication, rule-setting, and self-regulation. Therefore, schools may systematically train educators and act as informational and screening hubs for early signs or stages of problem behaviors, liaising with the parental community and mental health services, as is the case for other mental health disorders (i.e., depression and self-harm) in some 
countries (UK and NHS's Child and Adolescent Mental Health Services for young people and parents). Public policy may build on such evidence to shape and endorse the aforementioned initiatives. At the parental level, the findings may shed light on the fact that upbringing should focus on fostering a warm and supportive environment, improving parent-child communication and self-regulation, and encouraging a digital "diet" balanced with physical activity and other sources of self-worth, rather than overrelying on the gaming context to meet these demands.

The findings should be interpreted in light of several limitations. First, the sample was drawn from one source, where members could be more socially inclined individuals. Second, self-report data may: (a) include processed and reconceptualized adult recollections influenced by social desirability or lack of insight (Dunning, Heath, \& Suls, 2004; Hardt \& Rutter, 2004), and (b) present a bias toward underreporting, which was potentially the case for the prevalence of psychiatric comorbidity presented, being low compared to what appears in the existing literature (González-Bueso et al., 2018). Another limitation was sample size, due to the critical cut-offs and CSE being the only potential mediator examined. It is also important to include other covariates (i.e., peers, academic performance, and personality factors) that may account for a significant relationship between PAR and IGD. Additionally, the sample composition was highly skewed in terms of male gender. However, this reflects extant literature, which supports the predominance of males versus females in use and engagement but also in the development of the disorder and in vulnerability factors, despite growing evidence for higher female use (Dauphin \& Heller, 2010; Dong, Wang, Du, \& Potenza, 2018; Milani et al., 2018; Veltri, Krasnova, Baumann, \& Kalayamthanam, 2014). A significant limitation of this study is its cross-sectional design, particularly with respect to its attempt to establish causality and its direction between the variables examined. A cross-sectional study may generate only a non-causal inference, which may be further explored with a different study design or analytical methods (i.e., multivariate regression models). Therefore, future studies with longitudinal designs could follow specific developmental trajectories and highlight the role of family functioning across the various developmental stages and its relation to gaming.

In conclusion, the findings of this study underscore a potential etiological/causal relationship (mediation), rather than an observed interaction effect (moderation) between the chronologically distant variables of PAR and CSE on IGD. One potential pathway to IGD appears to be rooted in a deficient childhood that may lead to a depleted self-concept, which in turn may lead to addictive activity, highlighting a process and systems-oriented approach in the development and maintenance of the disorder.

Funding sources: No financial support was received for this study.

Authors' contribution: Mrs. MAT was involved in the study design, execution, analysis and interpretation of data, and the drafting and revision of the manuscript. Prof. MJ supervised the study. All authors contributed to the drafting, revised, and approved the final version of the manuscript as submitted.

Conflict of interest: The authors declare no conflict of interest.

Acknowledgements: The authors would like to thank Professor Ioannis Tsaousis for his invaluable comments and suggestions in conducting this study.

\section{REFERENCES}

Adams, B. L. M., Stavropoulos, V., Burleigh, T. L., Liew, L. W. L., Beard, C. L., \& Griffiths, M. D. (2018). Internet gaming disorder behaviors in emergent adulthood: A pilot study examining the interplay between anxiety and family cohesion. International Journal of Mental Health and Addiction. Advance online publication. 1-17. doi:10.1007/s11469018-9873-0

Allison, S. E., von Wahlde, L., Shockley, T., \& Gabbard, G. O. (2006). The development of the self in the era of the Internet and role-playing fantasy games. The American Journal of Psychiatry, 163(3), 381-385. doi:10.1176/appi.ajp.163.3.381

American Psychological Association. (2010). Ethical principles of psychologists and code of conduct. Washington, DC: American Psychological Association.

American Psychiatric Association. (2013). Diagnostic and statistical manual of mental disorders (DSM- $5^{\mathbb{B}}$ ) (5th ed.). Washington, DC: American Psychiatric Association.

Arnett, J. J. (2000). Emerging adulthood: A theory of development from the late teens through the twenties. American Psychologist, 55(5), 469-480. doi:10.1037//0003-066X.55.5.469

Arnett, J. J., Žukauskienè, R., \& Sugimura, K. (2014). The new life stage of emerging adulthood at ages 18-29 years: Implications for mental health. The Lancet Psychiatry, 1(7), 569-576. doi:10.1016/S2215-0366(14)00080-7

Bandura, A. (1977). Self-efficacy: Toward a unifying theory of behavioral change. Psychological Review, 84(2), 191-215. doi:10.1037/0033-295X.84.2.191

Barber, B. K., \& Thomas, D. L. (1986). Dimensions of fathers' and mothers' supportive behavior: The case for physical affection. Journal of Marriage and Family, 48(4), 783-794. doi:10.2307/ 352571

Baron, R. M., \& Kenny, D. A. (1986). The moderator-mediator variable distinction in social psychological research: Conceptual, strategic, and statistical considerations. Journal of Personality and Social Psychology, 51(6), 1173-1182. doi:10.1037/0022-3514.51.6.1173

Beard, C. L., Haas, A. L., Wickham, R. E., \& Stavropoulos, V. (2017). Age of initiation and Internet gaming disorder: The role of self-esteem. Cyberpsychology, Behavior, and Social Networking, 20(6), 397-401. doi:10.1089/cyber.2017.0011

Beard, C. L., \& Wickham, R. E. (2016). Gaming-contingent selfworth, gaming motivation, and Internet gaming disorder. Computers in Human Behavior, 61, 507-515. doi:10.1016/j.chb.2016.03.046 
Bessière, K., Seay, A. F., \& Kiesler, S. (2007). The ideal elf: Identity exploration in World of Warcraft. CyberPsychology \& Behavior, 10(4), 530-535. doi:10.1089/cpb.2007.9994

Biller, H. B., \& Borstelmann, L. J. (1967). Masculine development: An integrative review. Merrill-Palmer Quarterly, 13(4), 253-294.

Billieux, J., Thorens, G., Khazaal, Y., Zullino, D., Achab, S., \& Van der Linden, M. (2015). Problematic involvement in online games: A cluster analytic approach. Computers in Human Behavior, 43, 242-250. doi:10.1016/j.chb.2014.10.055

Billings, A. G., \& Moos, R. H. (1981). The role of coping responses and social resources in attenuating the stress of life events. Journal of Behavioral Medicine, 4(2), 139-157. doi:10.1007/BF00844267

Bleidorn, W., \& Schwaba, T. (2017). Personality development in emerging adulthood. In J. Specht (Ed.), Personality development across the lifespan (pp. 39-51). London, UK: Elsevier.

Blom, I., \& Bergman, A. (2013). Observing development: A comparative view of attachment theory and separationindividuation theory. In J. E. Bettmann \& D. D. Friedman (Eds.), Attachment-based clinical work with children and adolescents (pp. 9-43). New York, NY: Springer.

Bonnaire, C., \& Phan, O. (2017). Relationships between parental attitudes, family functioning and Internet gaming disorder in adolescents attending school. Psychiatry Research, 255, 104-110. doi:10.1016/j.psychres.2017.05.030

Booth, A., \& Amato, P. R. (1994). Parental gender role nontraditionalism and offspring outcomes. Journal of Marriage and Family, 56(4), 865-877. doi:10.2307/353599

Bowman, N. D., Schultheiss, D., \& Schumann, C. (2012). 'I'm attached, and I'm a good guy/gal!': How character attachment influences pro- and anti-social motivations to play massively multiplayer online role-playing games. Cyberpsychology, Behavior, and Social Networking, 15(3), 169-174. doi:10.1089/ cyber.2011.0311

Braun, B., Stopfer, J. M., Müller, K. W., Beutel, M. E., \& Egloff, B. (2016). Personality and video gaming: Comparing regular gamers, non-gamers, and gaming addicts and differentiating between game genres. Computers in Human Behavior, 55, 406-412. doi:10.1016/j.chb.2015.09.041

Brown, K. W., \& Ryan, R. M. (2003). The benefits of being present: Mindfulness and its role in psychological well-being. Journal of Personality and Social Psychology, 84(4), 822-848. doi:10.1037/0022-3514.84.4.822

Burnay, J., Billieux, J., Blairy, S., \& Laroi, F. (2015). Which psychological factors influence Internet addiction? Evidence through an integrative model. Computers in Human Behavior, 43, 28-34. doi:10.1016/j.chb.2014.10.039

Chak, K., \& Leung, L. (2004). Shyness and locus of control as predictors of Internet addiction and Internet use. CyberPsychology \& Behavior, 7(5), 559-570. doi:10.1089/cpb. 2004.7.559

Choi, E. J., Taylor, M. J., Hong, S.-B., Kim, C., Kim, J.-W., McIntyre, R. S., \& Yi, S.-H. (2018). Gaming-addicted teens identify more with their cyber-self than their own self: Neural evidence. Psychiatry Research, 279, 51-59. doi:10.1016/j. pscychresns.2018.05.012

Chong, C. H., Yeo, K. J., \& Mislan, N. (2014). A preliminary study on relationship between warmth parenting and self-esteem among young adults based on parental acceptance-rejection theory. IOSR Journal of Humanities and Social Science, 19(9),
51-57. Retrieved from https://pdfs.semanticscholar.org/9c0e/ 7c0820936efdd5ef5da0b92cc3ddb1b6a418.pdf

Chory, R. M., \& Goodboy, A. K. (2011). Is basic personality related to violent and non-violent video game play and preferences? Cyberpsychology, Behavior, and Social Networking, 14(4), 191-198. doi:10.1089/cyber.2010.0076

Colder Carras, M., Van Rooij, A. J., Spruijt-Metz, D., Kvedar, J., Griffiths, M. D., Carabas, Y., \& Labrique, A. (2018). Commercial video games as therapy: A new research agenda to unlock the potential of a global pastime. Frontiers in Psychiatry, 8, 300. doi:10.3389/fpsyt.2017.00300

Cole, S. H., \& Hooley, J. M. (2013). Clinical and personality correlates of MMO Gaming: Anxiety and absorption in problematic Internet use. Social Science Computer Review, 31(4), 424-436. doi:10.1177/0894439312475280

Connell, C. M., Gilreath, T. D., Aklin, W. M., \& Brex, R. A. (2010). Social-ecological influences on patterns of substance use among non-metropolitan high school students. American Journal of Community Psychology, 45, 36-48. doi:10.1007/ s10464-009-9289-x

Corder, K., Winpenny, E., Love, R., Brown, H. E., White, M., \& van Sluijs, E. (2017). Change in physical activity from adolescence to early adulthood: A systematic review and metaanalysis of longitudinal cohort studies. British Journal of Sports Medicine. Advance online publication. doi:10.1136/ bjsports-2016-097330

Coyne, S. M., Padilla-Walker, L. M., \& Howard, E. (2014). Media uses in emerging adulthood. In J. J. Arnett (Ed.), The Oxford handbook of emerging adulthood (Vol. 1). New York: Oxford University Press.

Dauphin, B., \& Heller, G. (2010). Going to other worlds: The relationships between videogaming, psychological absorption, and daydreaming styles. Cyberpsychology, Behavior, and Social Networking, 13(2), 169-172. doi:10.1089/cyber.2009.0065

Davis, R. A. (2001). A cognitive-behavioral model of pathological Internet use. Computers in Human Behavior, 17(2), 187-195. doi:10.1016/S0747-5632(00)00041-8

Day, I. (2017). A family systems approach to the understanding and treatment of Internet gaming disorder. The Family Journal, 25(3), 264-270. doi:10.1177/1066480717711108

Deci, E. L., \& Ryan, R. M. (1985). Intrinsic motivation and selfdetermination in human behavior. London, UK: Plenum.

Delfabbro, P., Stevenson, J., Malvaso, C., Duong, D., Winefield, H., Winefield, A., \& Hammarström, A. (2018). Who is doing well: Age 15 predictors of psychological and physical health in young adulthood. Australian Psychologist. Advance online publication. 1-11. doi:10.1111/ap.12369

Dong, G., Wang, L., Du, X., \& Potenza, M. N. (2018). Genderrelated differences in neural responses to gaming cues before and after gaming: Implications for gender-specific vulnerabilities to Internet gaming disorder. Social Cognitive and Affective Neuroscience, 13(11), 1203-1214. doi:10.1093/ scan/nsy084

Douglas, A. C., Mills, J. E., Niang, M., Stepchenkova, S., Byun, S., Ruffini, C., Lee, S. K., Loutfi, J., Lee, J.-K., Atallah, M., \& Blanton, M. (2008). Internet addiction: Meta-synthesis of qualitative research for the decade 1996-2006. Computers in Human Behavior, 24(6), 3027-3044. doi:10.1016/j.chb. 2008.05.009

Dunning, D., Heath, C., \& Suls, J. M. (2004). Flawed selfassessment: Implications for health, education, and the 
workplace. Psychological Science in the Public Interest, 5(3), 69-106. doi:10.1111/j.1529-1006.2004.00018.x

Dural, G., \& Yalcin, I. (2014). Investigation of relationship between parental acceptance and psychological adjustment among university students. Dusunen Adam, 27, 221-232. doi:10.5350/DAJPN2014270305

Engel, G. L. (1977). The need for a new medical model: A challenge for biomedicine. Science, 196(4286), 129-136. Retrieved from http://www.drannejensen.com/PDF/publications/ The $\% 20$ need $\% 20$ for $\% 20 \mathrm{a} \% 20$ new $\% 20$ medical $\% 20$ mode $\%$ $20-\% 20 \mathrm{~A} \% 20$ challenge $\% 20$ for $\% 20$ biomedicine.pdf

Erez, A., \& Judge, T. A. (2001). Relationship of core self-evaluations to goal setting, motivation, and performance. The Journal of Applied Psychology, 86(6), 1270-1279. doi:10.1037//00219010.86.6.1270

Estévez, A., Jáuregui, P., Sánchez-Marcos, I., López-González, H., \& Griffiths, M. D. (2017). Attachment and emotion regulation in substance addictions and behavioral addictions. Journal of Behavioral Addictions, 6(4), 534-544. doi:10.1556/2006. 6.2017 .086

Feng, W., Ramo, D. E., Chan, S. R., \& Bourgeois, J. A. (2017). Internet gaming disorder: Trends in prevalence 1998-2016. Addictive Behaviors, 75, 17-24. doi:10.1016/j.addbeh.2017. 06.010

Fritz, M. S., \& Mackinnon, D. P. (2007). Required sample size to detect the mediated effect. Psychological Science, 18(3), 233-239. doi:10.1111/j.1467-9280.2007.01882.x

Geng, J., Han, L., Gao, F., Jou, M., \& Huang, C.-C. (2018). Internet addiction and procrastination among Chinese young adults: A moderated mediation model. Computers in Human Behavior, 84, 320-333. doi:10.1016/j.chb.2018.03.013

Gervasi, A. M., Marca, L. L., Costanzo, A., Pace, U., Guglielmucci, F., \& Schimmenti, A. (2017). Personality and Internet gaming disorder: A systematic review of recent literature. Current Addiction Reports, 4(3), 293-307. doi:10.1007/ s40429-017-0159-6

Giaouzi, A., \& Giovazolias, T. (2015). Remembered parental rejection and social anxiety: The mediating role of partner acceptance-rejection. Journal of Child and Family Studies, 24(11), 3170-3179. doi:10.1007/s10826-015-0120-z

Giovazolias, T. (2014). The moderating role of parental power and prestige on the relationship between remembered parental acceptance and psychological adjustment among young Greek adults. Cross-Cultural Research, 48(3), 240-249. doi:10.1177/ 1069397114528299

González-Bueso, V., Santamaría, J., Fernández, D., Merino, L., Montero, E., \& Ribas, J. (2018). Association between Internet gaming disorder or pathological video-game use and comorbid psychopathology: A comprehensive review. International Journal of Environmental Research and Public Health, 15(4), 668. doi:10.3390/ijerph15040668

Graham, L. T., \& Gosling, S. D. (2013). Personality profiles associated with different motivations for playing World of Warcraft. Cyberpsychology, Behavior, and Social Networking, 16(3), 189-193. doi:10.1089/cyber.2012.0090

Granic, I., Lobel, A., \& Engels, R. C. M. E. (2014). The benefits of playing video games. American Psychologist, 69(1), 66-78. doi: $10.1037 / \mathrm{a} 0034857$

Grant, A. M., \& Sonnentag, S. (2010). Doing good buffers against feeling bad: Prosocial impact compensates for negative task and self-evaluations. Organizational Behavior and Human
Decision Processes, 111(1), 13-22. doi:10.1016/j.obhdp. 2009.07.003

Griffiths, M. D. (2005). A 'components' model of addiction within a biopsychosocial framework. Journal of Substance Use, 10(4), 191-197. doi:10.1080/14659890500114359

Griffiths, M. D., Kuss, D. J., \& Ortiz de Gortari, A. B. (2017). Videogames as therapy: An updated selective review of the medical and psychological literature. International Journal of Privacy and Health Information Management, 5(2), 71-96. doi:10.4018/IJPHIM.2017070105

Gruenewald, P. J., Remer, L. G., \& LaScala, E. A. (2013). Testing a social ecological model of alcohol use: The California 50-city study. Addiction, 109(5), 736-745. doi:10.1111/add.12438

Hardt, J., \& Rutter, M. (2004). Validity of adult retrospective reports of adverse childhood experiences: Review of the evidence. Journal of Child Psychology and Psychiatry, and Allied Disciplines, 45(2), 260-273. doi:10.1111/j.1469-7610.2004. 00218.x

Hayes, A. F. (2012). PROCESS: A versatile computational tool for observed variable mediation, moderation, and conditional process modeling [White paper]. Retrieved from http:// www.afhayes.com/public/process2012.pdf

Hayes, A. F. (2013). Introduction to mediation, moderation, and conditional process analysis: A regression-based approach. New York, NY: Guilford Press.

Hayes, A. F., \& Matthes, J. (2009). Computational procedures for probing interactions in OLS and logistic regression: SPSS and SAS implementations. Behavior Research Methods, 41(3), 924-936. doi:10.3758/BRM.41.3.924

Hein, A., \& Berman, N. (2016). The promise and peril of emerging adulthood: Introduction to the special issue. Cognitive and Behavioral Practice, 23(3), 263-269. doi:10.1016/j.cbpra. 2016.05.005

Henchoz, Y., Studer, J., Deline, S., N'Goran, A. A., Baggio, S., \& Gmel, G. (2016). Video gaming disorder and sport and exercise in emerging adulthood: A longitudinal study. Behavioral Medicine, 42(2), 105-111. doi:10.1080/08964289.2014.965127

Herodotou, C., Kambouri, M., \& Winters, N. (2014). Dispelling the myth of the socio-emotionally dissatisfied gamer. Computers in Human Behavior, 32, 23-31. doi:10.1016/j.chb.2013.10.054

Holt, L. J., Mattanah, J. F., \& Long, M. W. (2018). Change in parental and peer relationship quality during emerging adulthood: Implications for academic, social, and emotional functioning. Journal of Social and Personal Relationships, 35(5), 743-769. doi:10.1177/0265407517697856

Hughes, M. M., Blom, M., Rohner, R. P., \& Britner, P. A. (2005). Bridging parental acceptance-rejection theory and attachment theory in the preschool strange situation. Ethos, 33(3), 378-401. doi:10.1525/eth.2005.33.3.378

Hussain, Z., \& Pontes, H. M. (2018). Personality, internet addiction, and other technological addictions: A psychological examination of personality traits and technological addictions. In B. Bozoglan (Ed.), Psychological, social, and cultural aspects of Internet addiction (pp. 45-71). Hershey, PA: IGI Global. Retrieved from https://www.igi-global.com/chapter/personalityinternet-addiction-and-other-technological-addictions/193094

Hussain, Z., Williams, G. A., \& Griffiths, M. D. (2015). An exploratory study of the association between online gaming addiction and enjoyment motivations for playing massively multiplayer online role-playing games. Computers in Human Behavior, 50, 221-230. doi:10.1016/j.chb.2015.03.075 
Jeong, E. J., \& Lee, H. R. (2015). Addictive use due to personality: Focused on Big Five personality traits and game addiction. International Journal of Psychological and Behavioral Sciences, 9(6), 5. doi:10.1999/1307-6892/10002016

Judge, T. A., Bono, J. E., \& Locke, E. A. (2000). Personality and job satisfaction: The mediating role of job characteristics. Journal of Applied Psychology, 85(2), 237-249. doi:10.1037/ 0021-9010.85.2.237

Judge, T. A., Erez, A., Bono, J. E., \& Thoresen, C. J. (2002). Are measures of self-esteem, neuroticism, locus of control, and generalized self-efficacy indicators of a common core construct? Journal of Personality and Social Psychology, 83(3), 693-710. Retrieved from http://w.timothy-judge.com/CSEJPSP.pdf

Judge, T. A., Erez, A., Bono, J. E., \& Thoresen, C. J. (2003). The Core Self-Evaluations Scale: Development of a measure. Personnel Psychology, 56(2), 303-331. doi:10.1111/j.17446570.2003.tb00152.x

Judge, T. A., Hurst, C., \& Simon, L. S. (2009). Does it pay to be smart, attractive, or confident (or all three)? Relationships among general mental ability, physical attractiveness, core self-evaluations, and income. Journal of Applied Psychology, 94(3), 742-755. doi:10.1037/a0015497

Judge, T. A., Locke, E. A., \& Durnham, C. C. (1997). The dispositional causes of job satisfaction: A core evaluations approach. Research in Organizational Behavior, 19, 151-188.

Judge, T. A., Locke, E. A., Durham, C. C., \& Kluger, A. N. (1998). Dispositional effects on job and life satisfaction: The role of core evaluations. The Journal of Applied Psychology, 83(1), 17-34. doi:10.1037/0021-9010.83.1.17

Kammeyer-Mueller, J. D., Judge, T. A., \& Scott, B. A. (2009). The role of core self-evaluations in the coping process. Journal of Applied Psychology, 94(1), 177-195. doi:10.1037/a0013214

Kardefelt-Winther, D. (2014). The moderating role of psychosocial well-being on the relationship between escapism and excessive online gaming. Computers in Human Behavior, 38, 68-74. doi:10.1016/j.chb.2014.05.020

Kausar, R., \& Kazmi, S. R. (2011). Perceived parental acceptancerejection and self-efficacy of Pakistani adolescents. Journal of the Indian Academy of Applied Psychology, 37(2), 224-232.

Kazakova, S., Cauberghe, V., Pandelaere, M., \& De Pelsmacker, P. (2014). Players' expertise and competition with others shape the satisfaction of competence needs, gaming gratifications, and contingent self-esteem in a gaming context. Cyberpsychology, Behavior, and Social Networking, 17(1), 26-32. doi:10.1089/cyber.2012.0413

Khaleque, A., \& Rohner, R. P. (2002). Reliability of measures assessing the pancultural association between perceived parental acceptance-rejection and psychological adjustment: A metaanalysis of cross-cultural and intracultural studies. Journal of Cross-Cultural Psychology, 33(1), 87-99. doi:10.1177/ 0022022102033001006

Kim, E. J., Namkoong, K., Ku, T., \& Kim, S. J. (2008). The relationship between online game addiction and aggression, self-control and narcissistic personality traits. European Psychiatry, 23(3), 212-218. doi:10.1016/j.eurpsy.2007.10.010

Kim, H.-K., \& Davis, K. E. (2009). Toward a comprehensive theory of problematic Internet use: Evaluating the role of selfesteem, anxiety, flow, and the self-rated importance of Internet activities. Computers in Human Behavior, 25(2), 490-500. doi:10.1016/j.chb.2008.11.001
King, D. L., \& Delfabbro, P. H. (2014). The cognitive psychology of Internet gaming disorder. Clinical Psychology Review, 34(4), 298-308. doi:10.1016/j.cpr.2014.03.006

Ko, C.-H., Yen, J.-Y., Chen, C.-C., Chen, S.-H., \& Yen, C.-F. (2005). Gender differences and related factors affecting online gaming addiction among Taiwanese adolescents. The Journal of Nervous and Mental Disease, 193(4), 273-277. doi:10. 1097/01.nmd.0000158373.85150.57

Koo, D.-M. (2009). The moderating role of locus of control on the links between experiential motives and intention to play online games. Computers in Human Behavior, 25(2), 466-474. doi:10.1016/j.chb.2008.10.010

Koumoundourou, G., Tsaousis, I., \& Kounenou, K. (2011). Parental influences on Greek adolescents' career decision-making difficulties: The mediating role of core self-evaluations. Journal of Career Assessment, 19(2), 165-182. doi:10.1177/ 1069072710385547

Kuss, D. J., Griffiths, M. D., \& Binder, J. F. (2013). Internet addiction in students: Prevalence and risk factors. Computers in Human Behavior, 29(3), 959-966. doi:10.1016/j.chb.2012.12.024

Kuss, D. J., \& Lopez-Fernandez, O. (2016). Internet addiction and problematic Internet use: A systematic review of clinical research. World Journal of Psychiatry, 6(1), 143-176. doi:10.5498/wjp.v6.i1.143

Kuss, D. J., \& Pontes, H. M. (2019). Internet addiction. Evidencebased practice in psychotherapy (Vol. 41). Boston, MA: Hogrefe Publishing Corp.

Kuss, D. J., Shorter, G. W., van Rooij, A. J., Griffiths, M. D., \& Schoenmakers, T. M. (2013). Assessing Internet addiction using the parsimonious Internet addiction components modelA preliminary study. International Journal of Mental Health and Addiction, 12(3), 351-366. doi:10.1007/s11469-0139459-9

Kuss, D. J., Shorter, G. W., van Rooij, A. J., van de Mheen, D., \& Griffiths, M. D. (2014). The Internet addiction components model and personality: Establishing construct validity via a nomological network. Computers in Human Behavior, 39, 312-321. doi:10.1016/j.chb.2014.07.031

Kveton, P., \& Jelinek, M. (2016). Parenting styles and their relation to videogame addiction. International Journal of Psychological and Behavioural Sciences, 10(6), 1961-1964. doi:10.1999/ 1307-6892/10004682

Laconi, S., Pirs, S., \& Chabrol, H. (2017). Internet gaming disorder, motives, game genres and psychopathology. Computers in Human Behavior, 75(C), 652-659. doi:10.1016/j.chb.2017. 06.012

Laier, C., Wegmann, E., \& Brand, M. (2018). Personality and cognition in gamers: Avoidance expectancies mediate the relationship between maladaptive personality traits and symptoms of Internet-gaming disorder. Frontiers in Psychiatry, 9, 304. doi:10.3389/fpsyt.2018.00304

Layland, E. K., Hill, B. J., \& Nelson, L. J. (2018). Freedom to explore the self: How emerging adults use leisure to develop identity. The Journal of Positive Psychology, 13(1), 78-91. doi:10.1080/17439760.2017.1374440

Lemmens, J. S., Valkenburg, P. M., \& Peter, J. (2011). Psychosocial causes and consequences of pathological gaming. Computers in Human Behavior, 27(1), 144-152. doi:10.1016/j.chb. 2010.07.015

Li, D., Liau, A., \& Khoo, A. (2011). Examining the influence of actual-ideal self-discrepancies, depression, and escapism, on 
pathological gaming among massively multiplayer online adolescent gamers. Cyberpsychology, Behavior, and Social Networking, 14(9), 535-539. doi:10.1089/cyber.2010.0463

Li, W., Garland, E. L., \& Howard, M. O. (2014). Family factors in Internet addiction among Chinese youth: A review of English and Chinese-language studies. Computers in Human Behavior, 31, 393-411. doi:10.1016/j.chb.2013.11.004

Lo, S.-K., Wang, C.-C., \& Fang, W. (2005). Physical interpersonal relationships and social anxiety among online game players. CyberPsychology \& Behavior, 8(1), 15-20. doi:10.1089/ cpb.2005.8.15

Lyons-Ruth, K., \& Spielman, E. (2004). Disorganized infant attachment strategies and helpless-fearful profiles of parenting: Integrating attachment research with clinical intervention. Infant Mental Health Journal, 25(4), 318-335. doi:10.1002/ imhj.20008

MacKinnon, D. P., Lockwood, C. M., Hoffman, J. M., West, S. G., \& Sheets, V. (2002). A comparison of methods to test mediation and other intervening variable effects. Psychological Methods, 7(1), 83-104. doi:10.1037//1082-989X.7.1.83

Mageau, G. A., Carpentier, J., \& Vallerand, R. J. (2011). The role of self-esteem contingencies in the distinction between obsessive and harmonious passion. European Journal of Social Psychology, 41(6), 720-729. doi:10.1002/ejsp.798

Mallorquí-Bagué, N., Fernández-Aranda, F., Lozano-Madrid, M., Granero, R., Mestre-Bach, G., Baño, M., Pino-Gutiérrez, A. D., Gómez-Peña, M., Aymamí, N., Menchón, J. M., \& Jiménez-Murcia, S. (2017). Internet gaming disorder and online gambling disorder: Clinical and personality correlates. Journal of Behavioral Addictions, 6(4), 669-677. doi:10.1556/ 2006.6.2017.078

McMillin, J. (2017). The paradox of choice in emerging adulthood: Anxiety and ambivalence. Bowling Green, $\mathrm{OH}$ : Bowling Green State University. Retrieved from https://etd.ohiolink.edu/ !etd.send_file?accession=bgsu1499426843058909\&disposition= inline

Mehroof, M., \& Griffiths, M. D. (2010). Online gaming addiction: The role of sensation seeking, self-control, neuroticism, aggression, state anxiety, and trait anxiety. Cyberpsychology, Behavior, and Social Networking, 13(3), 313-316. doi:10. 1089/cyber.2009.0229

Milani, L., La Torre, G., Fiore, M., Grumi, S., Gentile, D. A., Ferrante, M., Miccoli, S., \& Di Blasio, P. (2018). Internet gaming addiction in adolescence: Risk factors and maladjustment correlates. International Journal of Mental Health and Addiction, 16(4), 888-904. doi:10.1007/s11469-017-9750-2

Mitchell, S., Gao, J., Hallett, M., \& Voon, V. (2016). The role of social novelty in risk seeking and exploratory behavior: Implications for addictions. PLoS One, 11(7), e0158947. doi:10.1371/journal.pone. 0158947

Monacis, L., de Palo, V., Griffiths, M. D., \& Sinatra, M. (2017). Exploring individual differences in online addictions: The role of identity and attachment. International Journal of Mental Health and Addiction, 15(4), 853-868. doi:10.1007/s11469017-9768-5

Müller, K. W., Beutel, M. E., Egloff, B., \& Wölfling, K. (2014). Investigating risk factors for Internet gaming disorder: A comparison of patients with addictive gaming, pathological gamblers and healthy controls regarding the Big Five personality traits. European Addiction Research, 20(3), 129-136. doi: $10.1159 / 000355832$
Müller, K. W., Beutel, M. E., \& Wölfling, K. (2014). A contribution to the clinical characterization of Internet addiction in a sample of treatment seekers: Validity of assessment, severity of psychopathology and type of co-morbidity. Comprehensive Psychiatry, 55(4), 770-777. doi:10.1016/j.comppsych.2014.01.010

Müller, K. W., Janikian, M., Dreier, M., Wölfling, K., Beutel, M. E., Tzavara, C., Richardson, C., \& Tsitsika, A. (2015). Regular gaming behavior and Internet gaming disorder in European adolescents: Results from a cross-national representative survey of prevalence, predictors, and psychopathological correlates. European Child \& Adolescent Psychiatry, 24(5), 565-574. doi:10.1007/s00787-014-0611-2

Nikolaou, I., \& Tsaousis, I. (2002). Emotional intelligence in the workplace: Exploring its effects on occupational stress and organizational commitment. The International Journal of Organizational Analysis, 10(4), 327-342. doi:10.1108/eb028956

Nuyens, F. M., Kuss, D. J., Lopez-Fernandez, O., \& Griffiths, M. D. (2018). The empirical analysis of non-problematic video gaming and cognitive skills: A systematic review. International Journal of Mental Health and Addiction. Advance online publication. 1-26. doi:10.1007/s11469-018-9946-0

Pavis, S., Cunningham-Burley, S., \& Amos, A. (1998). Health related behavioural change in context: Young people in transition. Social Science \& Medicine, 47(10), 1407-1418. doi:10.1016/S0277-9536(98)00257-3

Pietromonaco, P. R., \& Barrett, L. F. (2000). The internal working models concept: What do we really know about the self in relation to others? Review of General Psychology, 4(2), 155-175. doi:10.1037/1089-2680.4.2.155

Pontes, H. M., \& Griffiths, M. D. (2015a). Internet gaming disorder and its associated cognitions and cognitive-related impairments: A systematic review using PRISMA guidelines. Revista Argentina de Ciencias Del Comportamiento, 7(3), 102-118. Retrieved from https://revistas.unc.edu.ar/index.php/racc/ article/view/9236/Pontes

Pontes, H. M., \& Griffiths, M. D. (2015b). Measuring DSM-5 Internet gaming disorder: Development and validation of a Short Psychometric Scale. Computers in Human Behavior, 45, 137-143. doi:10.1016/j.chb.2014.12.006

Preacher, K. J., \& Hayes, A. F. (2004). SPSS and SAS procedures for estimating indirect effects in simple mediation models. Behavior Research Methods, Instruments, \& Computers, 36(4), 717-731. doi:10.3758/BF03206553

Preacher, K. J., \& Hayes, A. F. (2008). Asymptotic and resampling strategies for assessing and comparing indirect effects in multiple mediator models. Behavior Research Methods, 40(3), 879-891. doi:10.3758/BRM.40.3.879

Preacher, K. J., \& Kelley, K. (2011). Effect size measures for mediation models: Quantitative strategies for communicating indirect effects. Psychological Methods, 16(2), 93-115. doi: $10.1037 / \mathrm{a} 0022658$

Preacher, K. J., Rucker, D. D., \& Hayes, A. F. (2007). Addressing moderated mediation hypotheses: Theory, methods, and prescriptions. Multivariate Behavioral Research, 42(1), 185-227. doi:10.1080/00273170701341316

Przybylski, A. K., Weinstein, N., Murayama, K., Lynch, M. F., \& Ryan, R. M. (2012). The ideal self at play: The appeal of video games that let you be all you can be. Psychological Science, 23(1), 69-76. doi:10.1177/0956797611418676

Ream, G. L., Elliott, L. C., \& Dunlap, E. (2013). Trends in video game play through childhood, adolescence, and emerging 
adulthood. Psychiatry Journal, 2013, 1-7. doi:10.1155/2013/ 301460

Reinecke, L. (2009). Games and recovery: The use of video and computer games to recuperate from stress and strain. Journal of Media Psychology: Theories, Methods, and Applications, 21(3), 126-142. doi:10.1027/1864-1105.21.3.126

Roberts, B. W., \& Davis, J. P. (2016). Young adulthood is the crucible of personality development. Emerging Adulthood, 4(5), 318-326. doi:10.1177/2167696816653052

Rohner, R. P. (1986). The warmth dimension: Foundations of parental acceptance-rejection theory. Beverly Hills, CA: Sage Publications, Inc.

Rohner, R. P. (2005). Parental Acceptance-Rejection Questionnaire (PARQ): Test manual. In R.P. Rohner \& A. Khaleque (Eds.), Handbook for the study of parental acceptance and rejection (4th ed.). Storrs, CT: Rohner Research Publications.

Rohner, R.P., \& Khaleque, A. (Eds.). (2005). Handbook for the study of parental acceptance and rejection (4th ed.). Storrs, CT: Rohner Research Publications.

Rohner, R. P., \& Khaleque, A. (2010). Testing central postulates of parental acceptance-rejection theory (PARTheory): A metaanalysis of cross-cultural studies. Journal of Family Theory and Review, 2, 73-87. doi:10.1111/j.1756-2589.2010.00040.x

Rohner, R. P., Khaleque, A., \& Cournoyer, D. E. (2012). Introduction to parental acceptance-rejection theory, methods, evidence, and implications. Ronald and Nancy Rohner Center for the Study of interpersonal acceptance and rejection, University of Connecticut. Retrieved from http://www.csiar. uconn.edu

Rohner, R. P., \& Rohner, E. C. (1980). Worldwide tests of parental acceptance-rejection theory. Behavioral Science Research, 15, 1-21. doi:10.1177/106939718001500102

Rohner, R. P., \& Veneziano, R. A. (2001). The importance of father love: History and contemporary evidence. Review of General Psychology, 5(4), 382-405. doi:10.1037/1089-2680. 5.4.382

Rosenberg, M., Schooler, C., \& Schoenbach, C. (1989). Self-esteem and adolescent problems: Modeling reciprocal effects. American Sociological Review, 54(6), 1004. doi:10.2307/2095720

Rosopa, P. J., \& Schroeder, A. N. (2009). Core self-evaluations interact with cognitive ability to predict academic achievement. Personality and Individual Differences, 47(8), 1003-1006. doi:10.1016/j.paid.2009.07.028

Santesteban-Echarri, O., Ramos-Olazagasti, M. A., Eisenberg, R. E., Wei, C., Bird, H. R., Canino, G., \& Duarte, C. S. (2017). Parental warmth and psychiatric disorders among Puerto Rican children in two different socio-cultural contexts. Journal of Psychiatric Research, 87, 30-36. doi:10.1016/j. jpsychires.2016.12.008

Scerri, M., Anderson, A., Stavropoulos, V., \& Hu, E. (2018). Need fulfilment and Internet gaming disorder: A preliminary integrative model. Addictive Behaviors Reports, 100144, 1-7. doi:10.1016/j.abrep.2018.100144

Schimmenti, A., \& Caretti, V. (2017). Video terminal dissociative trance: Toward a psychodynamic understanding of problematic Internet use. Clinical Neuropsychiatry, 14(1), 64-72.

Schimmenti, A., Guglielmucci, F., Barbasio, C., \& Granieri, A. (2012). Attachment disorganization and dissociation in virtual worlds: A study on problematic Internet use among players of online role playing games. Clinical Neuropsychiatry, 9(5), 187-195.
Schimmenti, A., Passanisi, A., Gervasi, A. M., Manzella, S., \& Famà, F. I. (2014). Insecure attachment attitudes in the onset of problematic Internet use among late adolescents. Child Psychiatry \& Human Development, 45(5), 588-595. doi:10.1007/ s10578-013-0428-0

Schneider, L. A., King, D. L., \& Delfabbro, P. H. (2017). Family factors in adolescent problematic Internet gaming: A systematic review. Journal of Behavioral Addictions, 6(3), 321-333. doi:10.1556/2006.6.2017.035

Shrout, P. E., \& Bolger, N. (2002). Mediation in experimental and nonexperimental studies: New procedures and recommendations. Psychological Methods, 7(4), 422-445. doi:10.1037/ 1082-989X.7.4.422

Sincek, D., Humer-Tomasic, J., \& Duvnjak, I. (2017). Correlates of problematic gaming - Is there support for proneness to risky behaviours? Psychiatria Danubina, 29(3), 302-312. doi:10.24869/psyd.2017.302

Statista. (2018). Number of active video gamers worldwide from 2014 to 2021 (in millions). Retrieved from https://www. statista.com/statistics/748044/number-video-gamers-world/

Steiner, J. (1993). Psychic retreats: Pathological organizations in psychotic, neurotic and borderline patients: Pathological organisations in psychotic, neurotic and borderline patients. London, UK: New Library of Psychoanalysis.

Stetina, B. U., Kothgassner, O. D., Lehenbauer-Baum, M., \& Kryspin-Exner, I. (2011). Beyond the fascination of onlinegames: Probing addictive behavior and depression in the world of online-gaming. Computers in Human Behavior, 27(1), 473-479. doi:10.1016/j.chb.2010.09.015

Su, B., Yu, C., Zhang, W., Su, Q., Zhu, J., \& Jiang, Y. (2018). Father-child longitudinal relationship: Parental monitoring and Internet gaming disorder in Chinese adolescents. Frontiers in Psychology, 9, 95. doi:10.3389/fpsyg.2018.00095

Throuvala, M. A., Griffiths, M. D., Rennoldson, M., \& Kuss, D. J. (2018a). Clinical case study presentation on overcoming gaming addiction: When a quick fix is not enough (Vol. 7, p. 153). Paper presented at the 5th International Conference on Behavioral Addictions, Cologne, Germany.

Throuvala, M. A., Griffiths, M. D., Rennoldson, M., \& Kuss, D. J. (2018b). School-based prevention for adolescent Internet addiction: Prevention is the key. A systematic literature review. Current Neuropharmacology. Advance online publication. doi:10.2174/1570159X16666180813153806

Throuvala, M. A., Griffiths, M. D., Rennoldson, M., \& Kuss, D. J. (2018c). Treatment of problematic Internet use and patient characteristics: The case of Problematic Internet Use Unit 18 Ano in Greece (Vol. 7, p. 152). Paper presented at the 5th International Conference on Behavioral Addictions, Cologne, Germany.

Torres-Rodríguez, A., Griffiths, M. D., \& Carbonell, X. (2017). The treatment of Internet gaming disorder: A brief overview of the PIPATIC program. International Journal of Mental Health and Addiction, 16(4), 1000-1015. doi:10.1007/s11469-0179825-0

Tsaousis, I., Giavazolias, T., \& Mascha, K. (2010). Translation and psychometric properties of the child Parental AcceptanceRejection Questionnaire (Child PARQ) - Short Form in the Greek Language. Paper presented at the 3rd International Congress on Interpersonal Acceptance and Rejection, Padua, Italy.

Tsaousis, I., Nikolaou, I., Serdaris, N., \& Judge, T. A. (2007). Do the core self-evaluations moderate the relationship between 
subjective well-being and physical and psychological health? Personality and Individual Differences, 42(8), 1441-1452. doi:10.1016/j.paid.2006.10.025

Tsaousis, I., Karademas, E., \& Kalatzi, D. (2012). The role of core self-evaluations in the relationship between religious involvement and subjective well-being: A moderated mediation model. Mental Health Religion \& Culture, 16(2), 1-17. doi:10. 1080/13674676.2011.651716

Twenge, J. M., Gentile, B., DeWall, C. N., Ma, D., Lacefield, K., \& Schurtz, D. R. (2010). Birth cohort increases in psychopathology among young Americans, 1938-2007: A cross-temporal meta-analysis of the MMPI. Clinical Psychology Review, 30(2), 145-154. doi:10.1016/j.cpr.2009.10.005

Twenge, J. M., Joiner, T. E., Rogers, M. L., \& Martin, G. N. (2018). Increases in depressive symptoms, suicide-related outcomes, and suicide rates among U.S. adolescents after 2010 and links to increased new media screen time. Clinical Psychological Science, 6(1), 3-17. doi:10.1177/2167 702617723376

Twenge, J. M., \& Park, H. (2017). The decline in adult activities among U.S. adolescents, 1976-2016. Child Development. Advance online publication. doi:10.1111/cdev.12930

Van Rooij, A. J., Kuss, D. J., Griffiths, M. D., Shorter, G. W., Schoenmakers, M. T., \& Van De Mheen, D. (2014). The (co-) occurrence of problematic video gaming, substance use, and psychosocial problems in adolescents. Journal of Behavioral Addictions, 3(3), 157-165. doi:10.1556/JBA.3.2014.013

Veltri, N., Krasnova, H., Baumann, A., \& Kalayamthanam, N. (2014). Gender differences in online gaming: A literature review. Paper presented at the Twentieth Americas Conference on Information Systems, Savannah, Georgia, USA. Retrieved from http://aisel.aisnet.org/cgi/viewcontent.cgi?article $=1231$ \& context=amcis 2014

Wang, C.-W., Chan, C. L. W., Mak, K.-K., Ho, S.-Y., Wong, P. W. C., \& Ho, R. T. H. (2014). Prevalence and correlates of video and Internet gaming addiction among Hong Kong adolescents: A pilot study. TheScientificWorldJournal, 2014, 1-9. doi:10.1155/2014/874648
Wartberg, L., Kriston, L., Kramer, M., Schwedler, A., Lincoln, T., \& Kammerl, R. (2017). Internet gaming disorder in early adolescence: Associations with parental and adolescent mental health. European Psychiatry, 43, 14-18. doi:10.1016/j.eurpsy. 2016.12.013

Williams, D., Yee, N., \& Caplan, S. E. (2008). Who plays, how much, and why? Debunking the stereotypical gamer profile. Journal of Computer-Mediated Communication, 13(4), 993-1018. doi:10.1111/j.1083-6101.2008.00428.x

Wölfling, K., Müller, K., \& Beutel, M. (2010). Diagnostic measures: Scale for the Assessment of Internet and Computer Game Addiction (AICA-S). In D. Mücken, A. Teske, F. Rehbein, \& B. te Wild (Eds.), Prevention, diagnostics, and therapy of computer game addiction (pp. 212-215). Lengerich: Pabst Science.

Wölfling, K., Müller, K. W., \& Beutel, M. (2011). Reliability and validity of the Scale for the Assessment of Pathological Computer-Gaming (CSV-S). Psychotherapie, Psychosomatik, Medizinische Psychologie, 61(5), 216-224. doi:10.1055/s0030-1263145

World Health Organization. (2018). International Classification of Diseases, 11th Revision (ICD-11). Retrieved from www.who. int/classifications/icd/

Wu, Y., Sescousse, G., Yu, H., Clark, L., \& Li, H. (2018). Cognitive distortions and gambling near-misses in Internet gaming disorder: A preliminary study. PLoS One, 13(1), e0191110. doi:10.1371/journal.pone.0191110

Zhou, Q., Eisenberg, N., Losoya, S. H., Fabes, R. A., Reiser, M., Guthrie, I. K., Murphy, B. C., Cumberland, A. J., \& Shepard, S. A. (2002). The relations of parental warmth and positive expressiveness to children's empathy-related responding and social functioning: A longitudinal study. Child Development, 73(3), 893-915. doi:10.1111/1467-8624.00446

Zimmermann, P., \& Iwanski, A. (2014). Emotion regulation from early adolescence to emerging adulthood and middle adulthood: Age differences, gender differences, and emotionspecific developmental variations. International Journal of Behavioral Development, 38(2), 182-194. doi:10.1177/ 0165025413515405 